\title{
Challenges for pregnant Syrian refugees in Lebanon
}

Lena Abdin ${ }^{1}$

${ }^{1}$ School of Advanced International Studies, Johns Hopkins University, Washington, United States of America. (Correspondence to: lenaabdin@gmail. com).

Keywords: refugees, pregnancy, contraception, costs, healthcare

Citation: Abdin L. Challenges for pregnant Syrian refugees in Lebanon. East Mediterr Health J. 2018;24(10):1026-1029. https://doi. org/10.26719/2018.24.10.1026

Received: 02/06/16; accepted: 23/07/17

Copyright (c) World Health Organization (WHO) 2018. Some rights reserved. This work is available under the CC BY-NC-SA 3.o IGO license (https:// creativecommons.org/licenses/by-nc-sa/3.o/igo).

\section{Introduction}

During the summer of 2015 this study conducted research on various nongovernmental organizations (NGOs) and clinics operating on the ground that dealt with antenatal care for Syrian refugees. The main aim was to determine the challenges facing Syrian refugees who were pregnant and spending their term in a refugee environment.

Antenatal care is defined as "the branch of medicine that deals with the care of women during pregnancy, childbirth, and the recuperative period following delivery" (1). The main focus of this exploration is antenatal care, but in order to understand what it takes to treat a woman while she is pregnant, it is important to understand the circumstances of her pregnancy in the refugee setting context. The process was begun by conducting a literature review on what was already documented for this topic. Only one study had been published and another, conducted at Johns Hopkins, was in the process of publication $(2,3)$. The head of the first study was contacted and insight gained on where to do interviews on the ground and which NGOs were most responsive. Due to inaccessibility to makeshift camps or rural areas to conduct interviews, it was decided to focus on three different clinics around Beirut: the UNHCR designated maternal clinic, Caritas's designated maternal clinic, and a local Lebanese non-profit clinic. The directors of health departments were interviewed at UNHCR, Caritas, and Première Urgence-Aide Médicale Internationale and requesting access to their respective clinics to speak with patients.

At the clinics the patients were informed about the study in order to gauge their willingness to be interviewed. The women were given the option of remaining anonymous as some were afraid to give their full names for fear of repercussion back in the Syrian Arab Republic, where many refugees are viewed as "traitors" for leaving the country. Only the women who felt comfortable doing so wrote their names on the survey forms. The survey covered basic questions about the woman's living situation (where she lived and with how many people) and demographic information. It also covered the medical aspects of pregnancy such as how many visits she had had with the doctor and what vitamins/procedures she had had during her pregnancy.
The survey also asked if she had used birth control in the past and what her birth plan was. Fifty-three women were invited for interview and seven refused, giving a total of 42 women who were interviewed. For those who could not read, the questions were read aloud and answers recorded on the survey form.

A limitation of this survey was the location of interviews, which only took place in clinics. Another limitation was the size of the sample. With only 42 women interviewed, the results cannot be generalized to all Syrian refugee women in Lebanon - many do not have access to clinics. Furthermore, because this is an ongoing conflict and the number of Syrian refugees is growing daily, newly arrived refugees may have different characteristics and needs.

\section{Setting}

Awareness is one of the pertinent issues faced by organizations on the ground in Lebanon when it comes to contraception and antenatal care. Many of the women interviewed had either barely finished secondary education or had only primary education. Almost $100 \%$ of those interviewed had absolutely no knowledge of reproductive health prior to marriage. Even after marriage, most reproductive health information is taught through religious and cultural mechanisms (e.g. religion classes and women's social gatherings) rather than educational or scientific mechanisms.

One case stood out in this regard. A woman entered the doctor's office at the Caritas clinic with her mother and mother-in-law, and was complaining of pain and cramps. When asked if she was on any medication the response was ovary stimulants, which had been prescribed since she still was not pregnant after eight months of marriage. Ovary stimulants are dangerous and can harm the reproductive future of a woman (4), yet speed of conception was considered more important by the family than the health of the woman and her future child. The health risks involved in giving this type of medication to a most likely healthy woman were explained and that there were less invasive ways of trying to determine if there was infertility (like testing the male sperm). The three women listened andthen left, with the mother-in-law returning later to ask if the doctor could 
refill the prescription for the ovary stimulants because the previous doctor had refused out of concern for the daughter.

The lack of reproductive awareness and education is a major issue for many Middle Eastern countries. Cultural norms like delivering a son as the first child immediately after marriage to ensure the family's continued lineage and honour are still prevalent, even among desperate refugee populations. These norms do not disappear simply because these populations have been uprooted. This is why education and awareness are key when considering how to empower and teach refugees about reproduction, especially in a country with a population crisis as found in Lebanon.

\section{Contraception}

\section{Cost barriers}

A 2013 study found that the main barriers to contraceptive use in Lebanon for Syrian refugees were high cost, distance from services and absence of their desired method of contraception (5). The United Nations High Commissioner for Refugees (UNHCR) provides free access to family planning and contraception methods for registered refugees. Before the start of the conflict, the Syrian Arab Republic had an efficient health care system for middle- and lower-income families. Family planning methods and contraceptives were free and used by $58 \%$ of women (5). However, in Lebanon these numbers seem to have dropped. According to a United Nations Population Fund (UNFPA) report, among Syrian refugee women in Lebanon in 2012 only $37 \%$ of non-pregnant married women were using contraception (6). During the interviews conducted in Lebanon for this research, many Christian women claimed they had never used contraceptives for religious reasons. However, Muslim women claimed that the cost of contraceptives in Lebanon was too high. Furthermore, they were used to certain brands and to receiving the contraceptives for free.

Lebanon as host country is barely able to meet the demand for basic healthcare for Lebanese citizens, let alone for Syrian refugees, according to UNHCR (7). The Lebanese public-private healthcare system makes it all the more difficult to address the needs of refugees. Most clinics in Beirut are privately owned and operated and are very expensive for Syrian refugees. The women interviewed verified this on multiple occasions, citing the high costs of private healthcare. Uninsured Lebanese citizens obtain care through the Ministry of Health via public hospitals that cover up to $85 \%$ of the cost of hospital visits (8). The influx of Syrian refugees also exacerbates the challenges faced by Lebanese citizens seeking access to public healthcare (9).

Other issues are simply those of immediate need, whereby funds and services provided by organizations are usually directed at more life-threatening medical problems for Syrian refugees rather than issues such as contraception.

\section{Awareness and knowledge}

Contraception can help alleviate the already evident population crisis in Lebanon due to the immense influx of refugees. However, many Syrian refugees are simply uneducated about contraception. There is still a widely held belief that birth control prevents a woman from getting pregnant later on in life. However, field workers from the International Medical Corps in Beirut revealed that awareness sessions have helped in increasing knowledge of the positive outcomes of birth control as well as reducing pregnancy rates in refugee populations in rural areas. These sessions have been most effective when led by a religious leader in the community. Moreover, targeting men in their awareness sessions on contraception was important since it is usually the husband who decides whether or not his wife should utilize some form of birth control.

\section{Pregnancy}

\section{Cost barriers}

The cost of antenatal care itself is a huge burden for refugees, despite the subsidy paid by UNHCR. Antenatal care for registered Syrian women is covered for up to four antenatal care visits, $85 \%$ of laboratory costs and $75 \%$ of delivery costs. Pregnancy supplements and two ultrasound scans are provided free of charge. However, unregistered Syrian refugee women are only eligible for one visit to a primary healthcare centre supported by UNHCR. This is problematic for the following reasons.

First, there are many refugees illegally working and living in Lebanon that are not registered with UNHCR. There is no reliable data on the number of unregistered Syrian refugees currently in Lebanon. General estimates and media reports citing unnamed Lebanese officials put the number of Syrians living in Lebanon and not registered with UNHCR between 200000 and 400000 , although the reliability of and sources for these estimates, which do not distinguish between those in need of protection and/or assistance and those not in need, are unknown (10). The reasons for them being unregistered are numerous, but they most likely fear reprisal from the Syrian regime or reprisal against their family members still living in the Syrian Arab Republic due to their association with perceived "antiregime" institutions like the United Nations (UN) (11).

Second, even those registered could be living in a decentralized living situation such as makeshift camps where they do not have the ability to reach areas in which UNHCR operates, or just do not have information on where to access clinics or services. Antenatal care in the Syrian Arab Republic was not expensive and often free, while the cost of Lebanese antenatal care services is more expensive. A woman in Lebanon will have to spend the equivalent of US\$20 just to see a doctor and pay for supplements and transport, which is often more than half of a worker's weekly wage (12). 


\section{Awareness and knowledge}

Syrian women interviewed had difficulties knowing what kind of antenatal care was available, who was providing it, and how best to access it. The NGOs try to advertise discounted antenatal care and contraception to Syrian women utilizing mobile clinics to reach rural areas and camps. They distribute easy-to-read pamphlets and contact local religious leaders to encourage women to seek care.

Women interviewed had other reasons for not seeking antenatal care or taking essential pregnancy vitamins. In a region with a high prevalence of iron deficiency anaemia among reproductive age women, only $59.9 \%$ of women took iron tablets during their pregnancy. Even fewer $(41.2 \%)$ had an adequate diet of vitamins, minerals, and folic acid (13). Many of the women also had a distrust of the doctors and nurses in Lebanon. They were used to their family doctor in the Syrian Arab Republic and were simply unaccustomed to the facilities and practices of their new surroundings. Others did not think antenatal care was important to their baby's health and only visited the doctor when they thought there was something wrong.

\section{Delivery}

\section{Cost barriers}

High costs for antenatal care have Syrian refugee women going back to the Syrian Arab Republic for delivery, which is dangerous for both mother and child. Of the women interviewed, about 30\% said they could see themselves returning to their country to deliver their child, solely on the basis of cost efficiency. According to a study conducted by Johns Hopkins University, 93.6\% of Syrian refugee households observed incurred an out-of-pocket payment for the delivery of their child in Lebanon (14); the average payment was L£ 234294 (US\$155). Of the Syrian refugee households that reported out-of-pocket costs, $93.6 \%$ were serviced at private clinics or hospitals. No significant differences in the cost of delivery were noted between refugee households with all members registered with UNHCR and those with some or none of the members registered (14). However, it should be noted that a "greater proportion of refugees with all household members registered reported having a portion of the delivery cost paid on their behalf by an organization such as a humanitarian organization compared to households with some or none of the members registered, and these differences were marginally significant" (14).

\section{Conclusion}

Countries like Lebanon that host Syrian refugees have started to shift from emergency, short-term solutions to more long-term, integrative solutions. One such solution is mobile clinics. Refugees are spread over 1700 locations in Lebanon, making access challenging, even though the geographic spread of public health facilities is relatively good. Mobile clinics are used to alleviate the suffering of women in more hard-to-reach areas. They have also been sources of success when it comes to awareness and access to contraceptives. Humanitarian agencies conduct visits to remote areas with mobile clinics to reach the more vulnerable Syrian refugee populations. There are 23 mobile clinics operating throughout Lebanon through 12 agencies (IMC, AMEL, Caritas Liban, Makhzoumi Foundation, MSF-Ch, Humedica, Layan, MSF-Belgium, IMA, RI, LRC and Beyond) in 250 locations (as of July 2014). A mobile clinic team includes at least one medical doctor, one nurse, and/or one health educator or counsellor (15).

Safe and affordable healthcare for pregnant women demands a concerted effort on the part of the host government and NGOs on the ground to provide these services at no cost to these women, yet there is a funding gap (16). While it is too early to see the repercussions, there have been reports of Syrian women resorting to prostitution in Beirut and elsewhere, either by force or willingly (17).

In the absence of more funding, there should be active ways to encourage non-registered refugees to register with UNHCR in order to have access to family planning and lower-cost antenatal care. Incentives and communication strategies that foster UNHCR registration would help reduce the costs associated with antenatal care and delivery. More importantly, it is vital to give these women more education when it comes to family planning and pregnancy. As already mentioned, many of the women do not have adequate sexual or reproductive education and rely heavily on family members. The NGOs should commit to conducting more awareness sessions with incentives to attend such as a free service or receiving donated items. This way, aid workers would have the opportunity to educate women and men on reproductive health. Pamphlets and other means of communication could also help raise awareness. There have been case studies on sending SMS text messages to rural populations with awareness campaign slogans that have proven successful (18). The same could be done in this context; NGOs have the contact information of men and women registered with UNHCR and in clinics. In the absence of a physical meeting due to distance or lack of access to transportation, an SMS could be sent out with messages related to reproductive health or antenatal care.

Improving access to the UNHCR web of healthcare providers by reducing fees and improving access to free vital medication would help build trust within the community and allow refugees to have more options. Moreover, most generic medications in the Syrian Arab Republic are labelled in Arabic, while in Lebanon they are mostly labelled in English or French. It would be worthwhile having pharmacies associated with UNHCR or healthcare providers explain the medications to Syrian refugees who needed to take them and make them feel comfortable about using them.

The Syrian refugee crisis is not ending soon. Host countries like Lebanon and the NGOs operating within them need to shift from emergency short-term solutions to more long-term solutions and sustainability. This study was able to reach those women with access to a 
healthcare facility, but there are women who do not have the capabilities to ensure healthcare for their new-born and themselves. The Lebanese healthcare system is not readily accessible for refugees due to costs, while public hospitals are overwhelmed and international resources are limited. The only way to ensure the safety of pregnant refugees in Lebanon is to focus on Syrian households registering with UNHCR in order to allow them access to affordable antenatal care.

Funding: None.

Competing interests: None declared.

\section{References}

1. American Heritage Dictionary of the English Language. Boston: Houghton Mifflin; 2011.

2. Benage M, Greenough PG, Vinck P, Omeira N, Pham P. An assessment of antenatal care among Syrian refugees in Lebanon. Confl Health. 2015 Feb;9:8. PMID: 2574138

3. Maternal health care utilization among Syrian refugees in Lebanon and Jordan. Matern Child Health J. 2017 Sep;21(9):1798-807. PMID: 2870709

4. Institute of Medicine and National Research Council. Assessing the medical risks of human oocyte donation for stem cell research. Washington DC: The National Academies Press; 2007.

5. UN Population Fund. Response to the Syrian humanitarian crisis, Jan-April 2013. Geneva: UNHCR; 2013 (http://data.unhcr.org/ syrianrefugees/country.php?id=122, accessed 1 April 2016).

6. The number of Syrian refugees in Lebanon passes the 1 million mark. Geneva: UNHCR; 2014 (http://www.unhcr.org/en-us/news/ latest/2014/4/533cld5b9/number-syrian-refugees-lebanon-passes-1-million-mark.html, accessed 1 May 2018).

7. Syrian Arab Republic: WHO statistical profile. Geneva: World Health Organization; 2013.

8. Response to the Syrian humanitarian crisis in Lebanon. Geneva: UNFPA; 2016 (https://data2.unhcr.org/en/situations/syria/location/71, accessed 1 May 2016).

9. Samari G, The response to Syrian refugee women's health needs in Lebanon, Turkey and Jordan and recommendations for improved practice. New York: Humanity in Action Inc.; 2015.

10. Background paper on unregistered Syrian refugees in Lebanon. Beirut: Lebanon Humanitarian INGO Forum; 2014 (http://lhif. org/uploaded/News/d92fe3alb1dd46f2a281254fa551bdo9LHIF\%20Background\%20Paper\%200n\%20Unregistered\%20Syrian\%20 Refugees\%20(FINAL).pdf, accessed 5 May 2018).

11. Misery beyond the war zone: Life for Syrian refugees and displaced populations in Lebanon. Geneva: Médecins Sans Frontières; 2013 (http://www.doctorswithoutborders.org/sites/usa/files/Syria-Lebanon-Report-2013.pdf, accessed 5 May 2018).

12. Syrian refugees in Lebanon, "Pregnant women often have no idea where to go". News and stories 6 August 2013. Geneva: Médecins Sans Frontières; 2013 (http://www.doctorswithoutborders.org/news-stories/field-news/syrian-refugees-lebanon-pregnantwomen-often-have-no-idea-where-go, accessed 5 May 2018).

13. Benage M, Greenough PG, VinckP, Omeira N, Pham P. An assessment of antenatal care among Syrian refugees in Lebanon. Conflict and Health. 2015;9:8. https://doi.org/10.1186/s13031-015-0035-8

14. Syrian refugee and affected host population health access survey in Lebanon. Baltimore: Johns Hopkins University Bloomberg School of Public Health and Médicins du Monde; 2015 (https://data.unhcr.org/syrianrefugees/download.php?id=9550, accessed 5 May 2018).

15. Syria regional refugee response: health within the Lebanon refugee context. Geneva: UNHCR; 2014 (http://data.unhcr.org/syrianrefugees/country.php?id=122, accessed April 2016).

16. Funding requirements for 2016. Geneva: UNHCR; 2016 (http://data.unhcr.org/syrianrefugees/country.php?id=122, accessed 1 March 2016)

17. Mroue, B, Lebanon shocked over sex trafficking of young Syrian women. Associated Press; 13 April 2016. (http://bigstory.ap.org/ article/72253307caef4863858d659ce6686808/lebanon-shocked-over-sex-trafficking-young-syrian-women, accessed 5 May 2018).

18. Déglise C, Suggs LS, Odermatt P. Short message service (SMS) applications for disease prevention in developing countries. J Med Internet Res. 2012;14(1):e3. http://doi.org/10.2196/jmir.1823. 